\title{
Diagnostic implications of soluble triggering receptor expressed on myeloid cells- 1 in patients with acute respiratory distress syndrome and abdominal diseases: a preliminary observational study
}

\author{
Paula Ramirez ${ }^{1 *}$, Pedro Kot ${ }^{1}$, Veronica Marti ${ }^{1}$, Maria Dolores Gomez ${ }^{2}$, Raquel Martinez ${ }^{3}$, Vicente Saiz ,
} Francisco Catala ${ }^{4}$, Juan Bonastre', Rosario Menendez ${ }^{3}$

\begin{abstract}
Introduction: Patients admitted to the intensive care unit (ICU) because of acute or decompensated chronic abdominal disease and acute respiratory failure need to have the potential infection diagnosed as well as its site (pulmonary or abdominal). For this purpose, we measured soluble triggering receptor expression on myeloid cells1 (sTREM-1) in alveolar and peritoneal fluid.

Methods: Consecutive patients $(n=21)$ with acute or decompensated chronic abdominal disease and acute respiratory failure were included. sTREM was measured in alveolar (A-sTREM) and peritoneal (P-sTREM) fluids.

Results: An infection was diagnosed in all patients. Nine patients had a lung infection (without abdominal infection), 5 had an abdominal infection (without lung infection) and seven had both infections. A-sTREM was higher in the patients with pneumonia compared to those without pneumonia (1963 ng/ml (1010-3129) vs. 862 $\mathrm{ng} / \mathrm{ml}$ (333-1011); $P$ 0.019). Patients with abdominal infection had an increase in the P-sTREM compared to patients without abdominal infection (1941 ng/ml (1088-3370) vs. $305 \mathrm{ng} / \mathrm{ml}(288-459) ; P<0.001)$. A cut-off point of 900 $\mathrm{pg} / \mathrm{ml}$ of A-sTREM-1 had a sensitivity of $81 \%$ and a specificity of $80 \%$ (NPV 57\%; PPV 93\%, AUC 0.775) for the diagnosis of pneumonia. In abdominal infections, a cut-off point for P-sTREM of $900 \mathrm{pg} / \mathrm{ml}$ had the best results (sensitivity 92\%; specificity 100\%; NPV 90\%, PPV 100\%, AUC = 0.903).

Conclusions: STREM-1 measured in alveolar and peritoneal fluids is useful in assessing pulmonary and peritoneal infection in critical-state patients-A-sTREM having the capacity to discriminate between a pulmonary and an extrapulmonary infection in the context of acute respiratory failure.
\end{abstract}

\section{Introduction}

Patients with acute or decompensated chronic abdominal diseases can develop acute respiratory insufficiency, the etiology of which is difficult to identify. The difficulty arises because the condition is a result of acute respiratory failure, which is caused by an inflammatory response that is secondary to the abdominal pathology or that is due to nosocomial pneumonia [1,2]. In this context, the diagnosis of an abdominal or lung infection

\footnotetext{
* Correspondence: ramirez_pau@gva.es

'Department of Intensive Care Medicine, Hospital Universitario la Fe, Avda.

Campanar 21, 46009 Valencia, Spain

Full list of author information is available at the end of the article
}

can be complicated by several factors: (a) the systemic signs and symptoms of infection are non-specific, (b) the clinical data and the radiographic findings within the context of the patient in the intensive care unit (ICU) do not provide high specificity for either of the possibilities, and (c) the microbiological findings can be altered by previous antibiotic use. Hence, the therapeutic attitude, the management of the patient, and the prognosis would depend heavily on the identification of the focus of the infection.

The use of markers of systemic inflammation in the diagnosis and in therapeutic decision-making is progressively more valuable in clinical practice [3]. One of the

\section{C) Biomed Central}


more frequent applications is in the differential diagnosis between the inflammatory pictures of infection versus non-infection [4]. However, the measurement of inflammation markers in the circulation does not identify the focus of the infection [5]. Determinations of Creactive protein or procalcitonin (PCT) in the alveolar fluid have been useless to diagnose infection as cytokines [6-8]. Conversely, the measurement of the triggering receptor expressed on myeloid cells 1 (TREM-1) in alveolar, pleural, sinovial, and cerebrospinal fluids has, indeed, been demonstrated to be useful in several studies [5,9-12]. Also, an increase in TREM-1 has been observed in peritoneal fluid following the induction of peritonitis in an animal model [13].

Our hypothesis for this study is that the determination of soluble TREM-1 (sTREM-1) in alveolar and peritoneal fluids in seriously ill patients with abdominal diseases and respiratory insufficiency could be useful in identifying the existence of an infection. It is plausible that the local increase in STREM-1 would be higher in the presence of infection, and this would enable us to distinguish pulmonary or extrapulmonary infection as the etiology of acute respiratory failure.

The objective of the present study was to investigate the diagnostic value of STREM in bronchoalveolar lavage and peritoneal fluid in patients admitted to the ICU with severe respiratory insufficiency and an abdominal disease. We wished, as a secondary objective, to compare the diagnostic value of cutoff points of sTREM in both of these biological fluids.

\section{Materials and methods Design of the study}

We conducted a prospective observation study of consecutive cases.

\section{Study site and subjects}

The study was conducted in the ICU for a period of 18 months. The patients selected needed to fulfill the following criteria: (a) acute abdominal pathology, (b) respiratory insufficiency with acute respiratory distress syndrome (ARDS) criteria of not more than 3 days in duration, and (c) admission to the ICU. We excluded patients in whom it was not possible to extract a sample of peritoneal fluid. The protocol was reviewed and approved by the local ethics committee, and the patients (or their relatives) provided informed consent to participation in the study. The written consent included the permission to collect and publish (anonymously) personal data concerning the patients.

\section{Protocol for data collection}

The following data were collected: age, gender, chronic diseases, vital signs, Acute Physiology Score, Acute Physiology and Chronic Health Evaluation II (APACHE II) score [14], Sepsis-related Organ Failure Assessment (SOFA) score [15], presence or absence of systemic inflammatory response syndrome [16], data on gas exchange and the mode of mechanical ventilation, radiological assessments, and the score on the modified Clinical Pulmonary Infection Score (CPIS) [17]. With respect to the abdomen, data were collected via physical examination, and the intra-abdominal pressure was measured via vesical probe. Other data included radiological assessments, intraoperative findings, blood chemistry, and microbiology laboratory findings. With respect to the lung, data were collected on the macroscopic aspects of the respiratory secretions, the Gram bacteria staining of mini-bronchoalveolar lavage (mini-BAL) fluid sent to the microbiology laboratory, and the quantitative isolations in culture.

\section{Definitions}

Diagnosis of hospital-acquired pneumonia, the pneumonia associated with mechanical ventilation, or pneumonia related to the health-care provision was conducted in accordance with the criteria recommended by the American Thoracic Society and the Infectious Diseases Society of America [18]. The diagnosis of the abdominal infection focus was performed in accordance with the Centers for Disease Control and Prevention (Atlanta, GA, USA) criteria for gastrointestinal infection and for infections associated with surgery [19].

\section{Collection and processing of the isolated abdominal fluid} Fine-needle aspiration puncture was performed under echographic guidance by experienced interventional radiologists. After vortex mixing, the sample was separated into three aliquots: the first was stored at $-70^{\circ} \mathrm{C}$ until required for analysis, the second was sent for cytobiochemical analyses, and the third was sent to the microbiology laboratory.

\section{Collection and processing of the alveolar liquid}

The sample of alveolar liquid was obtained using a small (20 mL of physiologic saline) volume of bronchoalveolar lavage (mini-BAL) [20]. After vortex mixing, the sample was centrifuged into two phases: the supernatant was separated and frozen at $-70^{\circ} \mathrm{C}$ until required for analyses, and the infranatant was sent to the microbiology laboratory. The cutoff value of mini-BAL for the diagnosis of lung infection was $10^{3}$ colony-forming units per milliliter.

\section{Measurement of inflammation markers}

Serum PCT was measured with time-resolved amplified cryptate emission (TRACE) technology in a Kryptor analyzer (Brahms Diagnostica, Berlin, Germany). The sTREM-1 was determined by immunoassay with a 
combination monoclonal/polyclonal antibody of the IgG1 type raised against TREM-1 (R\&D Systems, Inc., Minneapolis, MN, USA). The assay was performed in accordance with the instructions of the manufacturer.

\section{Statistical analyses}

All statistical analyses were performed with SPSS version 15 software (SPSS, Inc., Chicago, IL, USA). The $\chi^{2}$ test was used for categorical variables, and the Student $t$ or Mann-Whitney test was used for continuous variables. The values for PCT and STREM-1 were expressed as medians with the interquartile ranges (25\% to $75 \%)$ in parenthesis. Diagnostic capacities of alveolar sTREM1, peritoneal sTREM-1, and the alveolar-to-peritoneal sTREM-1 ratios were evaluated with the receiver operating characteristic curves. Sensitivity and specificity as well as positive (PPV) and negative (NPV) predictive values were calculated.

\section{Results}

Twenty-two patients fulfilled the inclusion criteria. One patient was censored because of our inability to obtain abdominal fluid. The mean age ( \pm standard deviation) was $48.2 \pm 16.7$ years, and $57 \%(n=12)$ were males. Eleven patients $(52 \%)$ had a chronic abdominal disease, seven patients (33\%) had hepatic cirrhosis, and one patient each had intestinal graft-versus-host disease,
Budd-Chiari syndrome, cystic fibrosis, and intestinal lymphoma. The acute abdominal diseases diagnosed were spontaneous bacterial peritonitis in $29 \%$ of cases, acute enteritis in 19\%, acute pancreatitis in 14\%, digestive tract hemorrhage in $14 \%$, and acute hepatitis in $10 \%$, and 1 case each (5\%) had cholecystitis, hepatic abscess, and intestinal subocclusion. The mean score on the APACHE II scale on the day of admission to the ICU was $18.6 \pm 5.8$ points. The intra-ICU mortality was $76.2 \%$. Table 1 shows the individual characteristics of the patients in the study.

\section{General characteristics upon entry into the study}

The mean stay in the ICU was $4.04 \pm 2.3$ days, and the mean duration of ventilation was $2.85 \pm 1.2$ days. The mean body temperature was $38.3 \pm 1^{\circ} \mathrm{C}$, the leukocytes were $10,176 \pm 6,736$ cells $/ \mathrm{mL}$ (median 11,600, range 4,600 to 13,650 ), and the plasma PCT was $17.77 \pm 25.42$ $\mathrm{ng} / \mathrm{mL}$ (median 7.9 , range 1.84 to 18.96 ). The mean SOFA score was $12.8 \pm 3.4$ points. All of the cases required wide-spectrum antibiotic treatment and invasive mechanical ventilation with an elevated fraction of inspired oxygen $\left(\mathrm{FiO}_{2}=0.7 \pm 0.2\right.$ and positive endexpiratory pressure $=9 \pm 2.5 \mathrm{~mm} \mathrm{Hg}$ ). Fourteen patients $(66.7 \%)$ were in shock with a need for vasoactive drugs, and four (19\%) underwent the technique of continuous renal replacement therapy (Table 2).

Table 1 Baseline characteristics of the patients

\begin{tabular}{|c|c|c|c|c|c|}
\hline Case & Chronic abdominal pathology & Other complaints & Admission to hospital & APACHE II score & Exitus \\
\hline 1 & No & No & Hepatic lesions & 13 & Yes \\
\hline 3 & Intestinal GVHD & Acute myeloid leukemia & Sepsis & 15 & Yes \\
\hline 4 & Hepatic cirrhosis & No & Gastrointestinal bleeding & 24 & Yes \\
\hline 5 & No & Acute lymphatic leukemia & Enteritis & 19 & \\
\hline 6 & No & No & Acute pancreatitis & 18 & No \\
\hline 7 & Hepatic cirrhosis & AIDS & Gastrointestinal bleeding & 21 & Yes \\
\hline 8 & Hepatic cirrhosis & No & Gastrointestinal bleeding & 20 & No \\
\hline 9 & Budd-Chiari syndrome & No & Respiratory failure & 10 & Yes \\
\hline 10 & No & No & Acute pancreatitis & 20 & Yes \\
\hline 11 & No & No & Intestinal subocclusion & 25 & No \\
\hline 12 & No & Alcoholism & Acute pancreatitis & 23 & Yes \\
\hline 13 & No & AIDS & Acute hepatitis & 12 & Yes \\
\hline 14 & No & No & Paralyzed ileum & & Yes \\
\hline 15 & Hepatic cirrhosis & AIDS & Hydropic decompensation & 29 & Yes \\
\hline 16 & No & Acute myeloid leukemia & Sepsis & 19 & Yes \\
\hline 17 & Cystic fibrosis & Hepato-bipulmonary transplant & Hepato-bipulmonary transplant & 9 & Yes \\
\hline 18 & Hepatic cirrhosis & No & Cholecystitis & 11 & No \\
\hline 19 & Intestinal lymphoma & No & Acute hepatitis & 14 & No \\
\hline 20 & No & No & Acute pancreatitis & 25 & Yes \\
\hline 21 & Hepatic cirrhosis & No & Gastrointestinal bleeding & 19 & Yes \\
\hline 22 & Hepatic cirrhosis & No & Hydropic decompensation & 26 & Yes \\
\hline
\end{tabular}

Patient 2 was removed from the analyses because of our inability to aspirate peritoneal fluid. APACHE II, Acute Physiology and Chronic Health Evaluation II; GVHD, graft-versus-host disease. 
Table 2 Characteristics of the patients upon inclusion in the study

\begin{tabular}{|c|c|c|c|c|c|c|c|c|}
\hline Case & $\begin{array}{l}\text { SOFA } \\
\text { score }\end{array}$ & Antibiotics & $\begin{array}{l}\text { Vasoactive } \\
\text { drugs }\end{array}$ & CRRT & $\begin{array}{c}\text { Procalcitonin, } \mathrm{ng} / \\
\mathrm{mL}\end{array}$ & $\begin{array}{c}\text { Temperature, }^{\circ} \\
\text { C }\end{array}$ & $\begin{array}{c}\text { Leukocytes,/ } \\
\mathrm{mm}^{3}\end{array}$ & Final diagnosis \\
\hline 1 & 11 & Yes & Yes & No & 96.46 & 39.0 & 9,800 & Systemic infection $^{a}$ \\
\hline 3 & 14 & Yes & Yes & No & 40.9 & 37.0 & 1,100 & Systemic infection ${ }^{b}$ \\
\hline 4 & 12 & Yes & No & No & 1.28 & 36.4 & 7,600 & VAP \\
\hline 5 & 16 & Yes & No & No & 18.62 & 40.0 & 0 & Enteritis + VAP \\
\hline 6 & 12 & Yes & Yes & Yes & 15.0 & 38.6 & 21,200 & $\begin{array}{l}\text { VAP + infected } \\
\text { pancreatitis }\end{array}$ \\
\hline 7 & 13 & Yes & Yes & No & 3,054 & 38.8 & 11,700 & Nosocomial pneumonia \\
\hline 8 & 16 & Yes & Yes & No & 3.5 & 39.0 & 2,900 & VAP \\
\hline 9 & 14 & Yes & Yes & No & 10.38 & 28.0 & 20,400 & HAP \\
\hline 10 & 15 & Yes & Yes & Yes & 50.0 & 38.0 & 11,600 & $\begin{array}{l}\text { VAP }+ \text { infected } \\
\text { pancreatitis }\end{array}$ \\
\hline 11 & 9 & Yes & Yes & No & 4.53 & 37.8 & 14,100 & VAP \\
\hline 12 & 11 & Yes & No & Yes & 13.0 & 38.2 & 7,600 & Infected pancreatitis \\
\hline 13 & 11 & Yes & No & No & 0.833 & 38.0 & 12,700 & $\mathrm{SBP}$ \\
\hline 14 & 11 & Yes & Yes & No & 68.65 & 40.0 & 13,200 & Enteritis \\
\hline 15 & 21 & Yes & Yes & No & 19.3 & 37.6 & 12,400 & SBP \\
\hline 16 & 16 & Yes & Yes & No & 7.9 & 39.3 & 200 & Enteritis \\
\hline 17 & 6 & Yes & No & No & 0.784 & 36.0 & 6,600 & Systemic infection ${ }^{c}$ \\
\hline 18 & 7 & Yes & No & No & 0.49 & 38.8 & 11,900 & HAP \\
\hline 19 & 16 & Yes & Yes & No & 0.90 & 37.0 & 6,100 & HAP \\
\hline 20 & 12 & Yes & Yes & Yes & 10.74 & 38.8 & 23,200 & VAP \\
\hline 21 & 12 & Yes & No & No & 2.41 & 38.7 & 3,100 & VAP \\
\hline 22 & 14 & Yes & Yes & No & 4.44 & 38.0 & 16,300 & $V A P+S B P$ \\
\hline
\end{tabular}

Patient 2 was removed from the analyses because of our inability to aspirate peritoneal fluid. 'Systemic infection' indicates that the same infection affected both the abdomen and lungs: ${ }^{\mathrm{a}}$ septic thrombophlebitis of the portal vein by Salmonella tiphy with hematogenous pneumonia; ${ }^{\mathrm{b}}$ citomegaloviruses colitis and

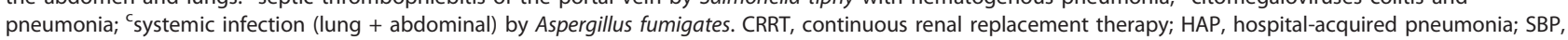
spontaneous bacterial peritonitis; SOFA, Sepsis-related Organ Failure Assessment; VAP, ventilator-associated pneumonia.

\section{Respiratory characteristics at the time of inclusion in the study}

The mean score on the CPIS was $5.4 \pm 2.4$ points (median 6 , range 3 to 7 ). The mean parameters of gas exchange were $\mathrm{pH}=7.33 \pm 0.11$, partial pressure of oxygen $\left(\mathrm{pO}_{2}\right)=42.2 \pm 12.7 \mathrm{~mm} \mathrm{Hg}$, partial pressure of carbon dioxide $\left(\mathrm{pCO}_{2}\right)=82.9 \pm 28.3 \mathrm{~mm} \mathrm{Hg}$, bicarbonate $=19.9 \pm 3.3 \mathrm{mmol} / \mathrm{L}$, and arterial partial pressure of oxygen $\left(\mathrm{PaO}_{2}\right) / \mathrm{FiO}_{2}$ ratio $=122.7 \pm 43.4$. Radiological findings were 8 localized condensations (38\%), 11 diffuse interstitial infiltrate $(52.5 \%)$, and 2 pleural effusions (9.5\%). Sixteen patients (76\%) had a definitive diagnosis of pulmonary infection: 7 of them also had an abdominal infection (in 5 of these, the infection was systemic and caused by the same microorganism). The median alveolar sTREM-1 was 1,437 (range 656 to 2,512) pg/mL (Table 3).

\section{Abdominal characteristics on the day of inclusion in the study}

The mean level of glucose in the peritoneal fluid was $157.64 \pm 77 \mathrm{mg} / \mathrm{dL}$ (median 161, range 104 to 330 ), and the mean of neutrophils was $406.5 \pm 1,108 \mathrm{cells} / \mathrm{mm}^{3}$ (median 51, range 10 to 249). The mean intra-abdominal pressure was $15.06 \mathrm{~mm} \mathrm{Hg}$. The diagnosis of abdominal infection was established in 12 patients (57\%); in 7 of these patients, the diagnosis of lung infection was established as well. The median value of s-TREM in peritoneal fluid was 933 (range 305 to 2,560) pg/mL (Table 4).

\section{Capacities of A-sTREM and P-sTREM to diagnose lung and abdominal infections, respectively}

Nine patients had lung infection (without abdominal infection), 5 had abdominal infection (without lung infection), and 7 had both infections. The patients with lung infection had a higher CPIS and a greater alveolar sTREM-1 ( $P=0.019$ and $P=0.019$, respectively) compared with those without lung infection. The patients with abdominal infection had a lower CPIS and increased plasma PCT and peritoneal sTREM ( $P=$ $0.002, P=0.018, P<0.001$, respectively) compared with those without abdominal infection (Tables 5 and 6).

The best cutoff point of alveolar sTREM for the diagnosis of lung infection was $900 \mathrm{pg} / \mathrm{mL}$ (sensitivity 81\%, specificity $80 \%$, PPV 93\%, NPV 57\%, and area under the curve [AUC] 0.775). In abdominal infection, the best cutoff point of peritoneal sTREM was $900 \mathrm{pg} / \mathrm{mL}$ (sensitivity 92\%, specificity 100\%, PPV 100\%, NPV 90\%, and AUC 0.903). 
Table 3 Respiratory characteristics of the patients

\begin{tabular}{|c|c|c|c|c|c|c|c|c|}
\hline Case & $\begin{array}{l}\text { Days under invasive } \\
\text { MV }\end{array}$ & $\begin{array}{l}\mathrm{PaO}_{2} / \\
\mathrm{FiO}_{2}\end{array}$ & Chest x-ray & CPIS & $\begin{array}{c}\text { Alveolar } \\
\text { microbiology }\end{array}$ & $\begin{array}{c}\text { Alveolar sTREM-1, } \\
\mathrm{pg} / \mathrm{mL}\end{array}$ & $\begin{array}{c}\text { Lung } \\
\text { infection }\end{array}$ & $\begin{array}{c}\text { Type of } \\
\text { infection }\end{array}$ \\
\hline 1 & 3 & 167 & Diffused interstitial & 3 & Salmonella tiphy & 1,437 & Yes & HAP \\
\hline 3 & 1 & 111 & Diffused interstitial & 3 & CMV & 434 & Yes & HAP \\
\hline 4 & 2 & 83 & Diffused interstitial & 6 & $\begin{array}{c}\text { Acinetobacter } \\
\text { baumannii }\end{array}$ & 2,475 & Yes & HAP \\
\hline 5 & 7 & 69 & LRL condensation & 8 & A. baumannii & 430 & Yes & VAP \\
\hline 6 & 6 & 180 & LLL condensation & 6 & A. baumannii & 2,166 & Yes & VAP \\
\hline 7 & 4 & 80 & Bilateral infiltrate & 6 & Escherichia coli & 1,755 & Yes & HAP \\
\hline 8 & 2 & 172 & Diffused interstitial & 5 & $\begin{array}{c}\text { Staphylococcus } \\
\text { aureus }\end{array}$ & 3,322 & Yes & HAP \\
\hline 9 & 2 & 111 & $\begin{array}{l}\text { Pulmonary } \\
\text { condensation, } \mathrm{R}\end{array}$ & 7 & Aspergillus fumigatus & 3,399 & Yes & HAP \\
\hline 10 & 3 & 108 & Bilateral infiltrate & 6 & $\begin{array}{l}\text { Haemophilus } \\
\text { influenzae }\end{array}$ & 3,758 & Yes & VAP \\
\hline 11 & 4 & 190 & LRL condensation & 6 & E. coli & 1,167 & Yes & HAP \\
\hline 12 & 2 & 93 & Bilateral infiltrate & 1 & Negative & 862 & No & \\
\hline 13 & 3 & 132 & Pleural effusion, $R$ & 2 & Negative & 229 & No & \\
\hline 14 & 1 & 160 & Diffused interstitial & 4 & Negative & 883 & No & \\
\hline 15 & 1 & 91 & Diffused interstitial & 4 & Candida albicans & 1,139 & No & \\
\hline 16 & 1 & 64 & Diffused interstitial & 4 & Negative & 437 & No & \\
\hline 17 & 1 & 195 & Diffused interstitial & 3 & A. fumigatus & 2,382 & Yes & HAP \\
\hline 18 & 1 & 125 & $\begin{array}{l}\text { Bilateral pleural } \\
\text { effusion }\end{array}$ & 9 & $\begin{array}{l}\text { Pseudomonas } \\
\text { aeruginosa }\end{array}$ & 175 & Yes & HAP \\
\hline 19 & 2 & 130 & Bi-basal condensation & 5 & A. fumigatus & 2,550 & Yes & HAP \\
\hline 20 & 6 & 58 & $\begin{array}{c}\text { Pulmonary } \\
\text { condensation, L }\end{array}$ & 8 & P. aeruginosa & 958 & Yes & VAP \\
\hline 21 & 6 & 95 & LRL condensation & 7 & A. baumannii & 450 & Yes & VAP \\
\hline 22 & 2 & 163 & LRL condensation & 8 & S. aureus & 3,986 & Yes & HAP \\
\hline
\end{tabular}

Patient 2 was removed from the analyses because of our inability to aspirate peritoneal fluid. CPIS, Clinical Pulmonary Infection Score; HAP, hospital-acquired pneumonia; L, left; LLL, lower left lobe; LRL, lower right lobe; MV, mechanical ventilation; $\mathrm{PaO}_{2} / \mathrm{FiO}_{2}$, arterial partial pressure of oxygen/fraction of inspired oxygen; R, right; VAP, ventilator-associated pneumonia.

\section{Diagnostic capacity of the alveolar-to-peritoneal sTREM ratio to discriminate the infection focus}

Nine patients had lung infection (without abdominal infection), 5 had abdominal infection (without lung infection), and 7 had both infections. All patients with just lung infection had an alveolar-to-peritoneal sTREM ratio of greater than 1 , and all patients with just abdominal infection had an alveolar-to-peritoneal sTREM ratio of less than 1 . However, patients with both infections had a huge variability, preempting any effective clinical application of the ratio.

\section{Discussion}

The results of our study demonstrate the usefulness (high predictive value) of measuring sTREM-1 in alveolar and peritoneal fluids in the diagnosis of pulmonary or abdominal infection (or both) in the context of ARDS. A-sTREM-1 was able to identify pneumonia as a pathogenic factor for ARDS. The relationships between the alveolar and peritoneal sTREM-1 values identified the focus of the infection.
The application of the sTREM-1 measurement for diagnosing pulmonary infections has had conflicting results. In the original study by Gibot and colleagues [5] and in subsequent studies [10], the measurement of alveolar sTREM achieved good results. Gibot and colleagues [5] found an area under the receiver operating characteristic curve for alveolar sTREM-1 of 0.93 (95\% confidence interval 0.92 to 0.95 ) in patients with community-acquired pneumonia or ventilator-associated pneumonia (VAP). In their study, Determann and colleagues [10] established a cutoff of $200 \mathrm{pg} / \mathrm{mL}$ of alveolar sTREM-1 with a sensibility of $75 \%$ and a specificity of $84 \%$ in the diagnosis of VAP. More recent studies by Anand and colleagues [21] and by others [22] did not reach the same conclusions. The discordance in the findings could be due to differences in the techniques for alveolar sample acquisition, in the method of measurement of sTREM-1, or in the type of patients included in the study. Anand and colleagues [21] segregated their patient population as those without VAP ( $n$ $=21)$, with definite VAP $(n=19)$, with indefinite VAP 
Table 4 Abdominal characteristics of the patients

\begin{tabular}{|c|c|c|c|c|c|c|c|}
\hline Case & $\begin{array}{c}\text { IAP, } \\
\text { mm Hg }\end{array}$ & $\begin{array}{c}\text { Neutrophils in } \\
\text { peritoneal fluid, } \mathrm{mm}^{3}\end{array}$ & $\begin{array}{l}\text { Glucose in peritoneal } \\
\text { fluid, } \mathrm{mg} / \mathrm{dL}\end{array}$ & $\begin{array}{l}\text { Peritoneal fluid } \\
\text { microbiology }\end{array}$ & $\begin{array}{c}\text { Peritoneal sTREM- } \\
1, \mathrm{pg} / \mathrm{mL}\end{array}$ & $\begin{array}{l}\text { Abdominal } \\
\text { infection }\end{array}$ & $\begin{array}{c}\text { Type of } \\
\text { infection }\end{array}$ \\
\hline 1 & & 130 & & Salmonella tiphy & 305 & Yes & $\begin{array}{c}\text { Hepatic } \\
\text { abscesses }\end{array}$ \\
\hline 3 & 15 & 1,670 & 228 & Polymicrobial & 2,871 & Yes & Colitis CMV \\
\hline 4 & 18 & 0 & 179 & Negative & 482 & No & \\
\hline 5 & 18 & & & $\begin{array}{l}\text { Acinetobacter } \\
\text { baumannii }\end{array}$ & 935 & Yes & Enteritis \\
\hline 6 & & 103 & 154 & A. baumannii & 1,242 & Yes & $\begin{array}{l}\text { Pancreatic } \\
\text { infection }\end{array}$ \\
\hline 7 & 18 & 10 & 238 & Negative & 445 & No & \\
\hline 8 & & 10 & 128 & Negative & 288 & No & \\
\hline 9 & 13 & 30 & 45 & Negative & 459 & No & \\
\hline 10 & 22 & 12,700 & & Negative & 3,474 & Yes & $\begin{array}{l}\text { Pancreatic } \\
\text { infection }\end{array}$ \\
\hline 11 & & 16 & 248 & Negative & 227 & No & \\
\hline 12 & 15 & 0 & 127 & Enterococcus faecalis & 3,267 & Yes & $\begin{array}{l}\text { Pancreatic } \\
\text { infection }\end{array}$ \\
\hline 13 & 11 & 544 & 93 & Negative & 1,423 & Yes & SBP \\
\hline 14 & 11 & & & Negative & 2,250 & Yes & Enteritis $^{a}$ \\
\hline 15 & 7 & 462 & 34 & Negative & 1,633 & Yes & SBP \\
\hline 16 & 17 & 0 & 186 & Negative & 933 & Yes & Enteritis $^{\mathrm{b}}$ \\
\hline 17 & & & & $\begin{array}{c}\text { Candida krusei, } \\
\text { Enterococcus faecium }\end{array}$ & 3,634 & Yes & Enteritis $^{c}$ \\
\hline 18 & 11 & 51 & 169 & Negative & 305 & No & \\
\hline 19 & 25 & 249 & 108 & Negative & 301 & No & \\
\hline 20 & 14 & 10 & & Negative & 854 & No & \\
\hline 21 & 14 & 148 & 285 & Negative & 174 & No & \\
\hline 22 & 12 & 4,365 & 30 & Escherichia coli & 4,406 & Yes & SBP \\
\hline
\end{tabular}

Patient 2 was removed from the analyses because of our inability to aspirate peritoneal fluid. ${ }^{a}$ Diagnosed from surgical findings; ${ }^{b}$ diagnosed from necropsy findings; 'clinical and microbiological diagnoses. CMV, cytomegalovirus; IAP, intra-abdominal pressure; SBP, spontaneous bacterial peritonitis; sTREM-1, soluble triggering receptor expressed on myeloid cells 1 .

$(n=56)$, and with alveolar hemorrhage $(n=9)$ and analyzed only the first two of these groups. Although the group with VAP showed higher levels of sTREM-1 $(171.9 \pm 158.7 \mathrm{pg} / \mathrm{mL})$ than the group without VAP $(96.7 \pm 76.2 \mathrm{pg} / \mathrm{mL})$, this difference did not reach statistical significance $(P=0.06)$ [21]. In our study, the patients with lung infection had a higher level of alveolar STREM than the patients without lung infection (mean $1,963 \mathrm{pg} / \mathrm{mL}$, interquartile range 1,010 to 3,129 versus $862 \mathrm{pg} / \mathrm{mL}$, interquartile range 333 to 1,$011 ; P=$ $0.019)$. Of note is that the values of sTREM-1 observed in our study do not compare with those observed by Anand and colleagues [21], who used the same analytical method as we did (that is, enzyme-linked immunoabsorbent assay). The differences could be due to the extreme status of our patient population (SOFA score $12.8 \pm 3.4$ ); the study of Anand and colleagues does not report SOFA score. With a cutoff point of $900 \mathrm{pg} / \mathrm{mL}$, the specificity is high and the PPV reaches $100 \%$.

The measurement of STREM-1 in peritoneal fluid as a diagnostic method has been less studied. It has been tested in an animal model in which the induction of

Table 5 Identification of pulmonary (alveolar) and abdominal (peritoneal) infection

\begin{tabular}{|c|c|c|c|c|c|c|}
\hline & \multicolumn{3}{|c|}{ Lung infection } & \multicolumn{3}{|c|}{ Abdominal infection } \\
\hline & Yes & No & $P$ value & Yes & No & $P$ value \\
\hline CPIS & $6.5(3.7-7.7)$ & $4(1.5-4.5)$ & 0.019 & $3.5(3.5-5.7)$ & $7(6-8)$ & 0.002 \\
\hline Serum PCT, ng/mL & $4.5(1.9-16.8)$ & $13(7.9-19.3)$ & 0.409 & $16.8(6.2-45.4)$ & $3.05(6-8)$ & 0.018 \\
\hline A-sTREM, pg/mL & $1,963(1,010-3,129$ & $862(333-1,011)$ & 0.019 & $1,011(435-2,274)$ & $1,760(1,167-2,550)$ & 0.177 \\
\hline P-sTREM, pg/mL & 470 (303-2056) & $1,633(1,423-2,250)$ & 0.117 & $1,941(1,088-3,370)$ & $305(288-459)$ & $<0.001$ \\
\hline
\end{tabular}

A-sTREM, alveolar soluble triggering receptor expressed on myeloid cells; CPIS, Clinical Pulmonary Infection Score; PCT, procalcitonin; P-sTREM, peritoneal soluble triggering receptor expressed on myeloid cells. 
Table 6 Diagnostic capacity of alveolar STREM and peritoneal sTREM

\begin{tabular}{lcc}
\hline & $\begin{array}{c}\text { Abdominal infection } \\
\text { Peritoneal sTREM } \\
\mathbf{2 9 0 0} \mathbf{~ p g / m L}\end{array}$ & $\begin{array}{c}\text { Lung infection } \\
\text { Alveolar sTREM } \\
\mathbf{2 9 0 0 ~} \mathbf{~ g / m L}\end{array}$ \\
\hline Sensitivity & $92 \%$ & $81 \%$ \\
Specificity & $100 \%$ & $80 \%$ \\
Positive predictive value & $100 \%$ & $93 \%$ \\
Negative predictive value & $90 \%$ & $57 \%$ \\
Area under the curve & $0.903(0.078)$ & $0.775(0.124)$ \\
\hline
\end{tabular}

sTREM, soluble triggering receptor expressed on myeloid cells.

peritonitis provoked an increase in the STREM-1 in peritoneal fluid [13]. Recently, Determann and colleagues [23] analyzed the capacity of peritoneal sTREM-1 to diagnose the persistence of secondary peritonitis post-surgery. The authors, in a sequential study of sTREM-1, observed that the patients with persistent infection at 48 hours post-surgery had a significantly higher median sTREM-1 (319 versus $85 \mathrm{pg} / \mathrm{mL} ; P=$ $0.001)$. We confirmed that patients with abdominal infection had elevated levels of peritoneal sTREM-1 of $1,941 \mathrm{pg} / \mathrm{mL}$ (interquartile range 1,088 to 3,370 ) versus $305 \mathrm{pg} / \mathrm{mL}$ (interquartile range 288 to 459$)(P<0.001)$. Furthermore, with a cutoff point of at least $900 \mathrm{pg} / \mathrm{mL}$, the diagnostic value showed high sensitivity $(92 \%)$, specificity (100\%), PPV (100\%), and NPV (90\%).

As expected, body temperature and plasma leukocyte counts were ineffective in identifying the infection focus. Elevated levels of plasma PCT were associated with abdominal infection, whereas $60 \%$ of the patients with pulmonary infection had a serum PCT level of less than $2.5 \mathrm{ng} / \mathrm{mL}$.

In our study, we used the measurement of sTREM-1 in alveolar and peritoneal fluids to discriminate the etiology of acute respiratory failure. However, the relatively high percentage of patients who have a systemic infection coexisting with abdominal and pulmonary infections complicates this objective. All patients with lung infection alone had an alveolar-to-peritoneal sTREM ratio of greater than 1 , and all patients with abdominal infection alone had an alveolar-to-peritoneal sTREM ratio of less than 1 . However, patients with both infections had a huge variability, preempting an effective clinical application of the ratio.

The principal limitation of our study is the small sample size. This important limitation, which precludes the generalization of the findings, is partially balanced by the novelty of the two aspects of the study design (that is, the application of sTREM-1 to the diagnosis of abdominal infection and the concomitant determination of the STREM-1 in two different sites to establish the infection focus). Our results need to be corroborated in a study with a larger sample size. The second limitation is the heterogeneity of our cohort. We included neutropenic patients in whom the usefulness of sTREM-1 has not been established. However, in our neutropenic patients, peritoneal and alveolar sTREM-1 levels showed results similar to those in non-neutropenic patients. Although the diagnosis of infection had been performed in accordance with established criteria, the microbiology results could have been affected by the generalized use of broad-spectrum antibiotics.

\section{Conclusions}

The results of our study show that the measurement of sTREM-1 is useful in the diagnosis of pulmonary infection and of abdominal infection in the context of severe acute respiratory failure. Further studies with a larger sample sizes are fully warranted to confirm the usefulness of sTREM-1 found in this preliminary study. Moreover, on the basis of our findings, the accuracy of this marker in neutropenic patients should be explored.

\section{Key messages}

- Alveolar soluble triggering receptor expressed on myeloid cells 1 (sTREM-1) is useful in diagnosing lung infections in the context of acute respiratory distress syndrome.

- Peritoneal sTREM-1 is capable of identifying an abdominal infection, including those developed in the setting of a chronic abdominal disease as spontaneous bacterial peritonitis in patients with hepatic cirrhosis.

- sTREM-1 seems to be the ideal biomarker to identify the site of infection in critical care patients when measured in fluids coming from the suspected tissues.

\section{Abbreviations}

APACHE II: Acute Physiology and Chronic Health Evaluation II; ARDS: acute respiratory distress syndrome; AUC: area under the curve; CPIS: Clinical Pulmonary Infection Score; $\mathrm{FiO}_{2}$ : fraction of inspired oxygen; ICU: intensive care unit; mini-BAL: mini-bronchoalveolar lavage; NPV: negative predictive value; PCT: procalcitonin; PPV: positive predictive value; SOFA: Sepsis-related Organ Failure Assessment; sTREM-1: soluble triggering receptor expressed on myeloid cells 1; TREM-1: triggering receptor expressed on myeloid cells 1; VAP: ventilator-associated pneumonia.

\section{Acknowledgements}

Written consent for publication was obtained from the patients or their relatives. We thank the ICU nursing staff of the Hospital Universitario la Fe for their assistance in patient care and in conducting the study. Editorial assistance was provided by Peter $\mathrm{R}$ Turner, whose services were paid for by the in-house Fundación Hospital La Fe. This research was supported, in part, by CIBERES, Fundación Hospital La Fe.

\section{Author details}

${ }^{1}$ Department of Intensive Care Medicine, Hospital Universitario la Fe, Avda. Campanar 21, 46009 Valencia, Spain. ${ }^{2}$ Department of Microbiology, Hospital Universitario la Fe, Avda. Campanar 21, 46009 Valencia, Spain. ${ }^{3}$ Department of Pneumology, Hospital Universitario la Fe, Avda. Campanar 21, 46009 
Valencia, Spain. ${ }^{4}$ Department of Radiology, Hospital Universitario la Fe, Avda. Campanar 21, 46009 Valencia, Spain.

\section{Authors' contributions}

$P R, J B$, and RMe contributed to the design of the study, analysis of the data, and manuscript preparation. PK and VM contributed to patient recruitment and manuscript preparation. MDG contributed to analysis of biomarkers (sTREM). RMa contributed to patient recruitment and sample aspiration. VS and FC contributed to patient recruitment and peritoneal liquid aspiration. All authors read and approved the final manuscript.

\section{Competing interests}

The authors declare that they have no competing interests.

Received: 29 November 2010 Revised: 5 January 2011

Accepted: 4 February 2011 Published: 4 February 2011

\section{References}

1. Neumann B, Zantl N, Veihelmann A, Emmanuilidis K, Pfeffer $K$, Heidecke CD, Holzmann B: Mechanisms of acute inflammatory lung injury induced by abdominal sepsis. Int Immunol 1999, 11:217-227.

2. Arozullah AM, Khuri SF, Henderson WG, Daley J: Development and validation of a multifactorial risk index for predicting postoperative pneumonia after major noncardiac surgery. Ann Intern Med 2001, 135:847-857.

3. Simon L, Gauvin F, Amre DK, Saint-Louis P, Lacroix J: Serum procalcitonin and C-reactive protein levels as markers of bacterial infection: a systematic review and meta-analysis. Clin Infect Dis 2004, 39:206-217.

4. Brunkhorst FM, Eberhard OK, Brunkhorst R: Discrimination of infectious and noninfectious causes of early acute respiratory distress syndrome by procalcitonin. Crit Care Med 1999, 27:2172-2176.

5. Gibot S, Cravoisy A, Levy B, Bene MC, Faure G, Bollaert PE: Soluble triggering receptor expressed on myeloid cells and the diagnosis of pneumonia. N Engl J Med 2004, 350:451-458.

6. Duflo F, Debon R, Monneret G, Bienvenu J, Chassard D, Allaouchiche B: Alveolar and serum procalcitonin: diagnostic and prognostic value in ventilator-associated pneumonia. Anesthesiology 2002, 96:74-79.

7. Ramirez P, Garcia MA, Ferrer M, Aznar J, Valencia M, Sahuquillo JM, Menéndez $R$, Asenjo MA, Torres A: Sequential measurements of procalcitonin levels in diagnosing ventilator-associated pneumonia. Eur Respir J 2008, 31:356-362.

8. Ramírez P, Ferrer M, Gimeno R, Tormo S, Valencia M, Piñer R, Menendez R, Torres A: Systemic inflammatory response and increased risk for ventilator-associated pneumonia: a preliminary study. Crit Care Med 2009, 37:1691-1695.

9. Determann RM, Weisfelt $M$, de Gans J: Soluble triggering receptor expressed on myeloid cells 1: a biomarker for bacterial meningitis. Intensive Care Med 2006, 32:1243-1247.

10. Determann RM, Millo JL, Gibot S, Korevaar JC, Vroom MB, van der Poll T, Garrard CS, Schultz MJ: Serial changes in soluble triggering receptor expressed on myeloid cells in the lung during development of ventilator-associated pneumonia. Intensive Care Med 2005, 31:1495-1500.

11. Bishara J, Goldberg E, Ashkenazi S, Yuhas Y, Samra Z, Saute M, Shaked H: Soluble triggering receptor expressed on myeloid cells-1 for diagnosing empyema. Ann Thorac Surg 2009, 87:251-254.

12. Collins CE, La DT, Yang HT, Massin F, Gibot S, Faure G, Stohl W: Elevated synovial expression of triggering receptor expressed on myeloid cells-1 (TREM-1) in patients with septic arthritis or rheumatoid arthritis. Ann Rheum Dis 2009, 68:1768-1774.

13. Gibot S, Massin F, Le Renard P, Béné MC, Faure GC, Bollaert PE, Levy B: Surface and soluble triggering receptor expressed on myeloid cells-1: expression patterns in murine sepsis. Crit Care Med 2005, 33:1787-1793.

14. Knaus WA, Draper EA, Wagner DP, Zimmerman JE: APACHE II: a severity of disease classification system. Crit Care Med 1985, 13:818-829.

15. Vincent $J$, Moreno R, Takala J, Willatts $S$, De Mendonça A, Bruining H, Reinhart CK, Suter PM, Thijs LG: The SOFA (Sepsis-related Organ Failure Assessment) score to describe organ dysfunction/failure. On behalf of the Working Group on Sepsis-Related Problems of the European Society of Intensive Care Medicine. Intensive Care Med 1996, 22:707-710.

16. Levy MM, Fink MP, Marshall JC, Abraham E, Angus D, Cook D, Cohen J, Opal SM, Vincent JL, Ramsay G, SCCM/ESICM/ACCP/ATS/SIS: 2001 SCCM/
ESICM/ACCP/ATS/SIS International Sepsis Definitions Conference. Crit Care Med 2003, 31:1250-1256

17. Luna CM, Blanzaco D, Niederman MS, Matarucco W, Baredes NC, Desmery P, Palizas F, Menga G, Rios F, Apezteguia C: Resolution of ventilator-associated pneumonia: prospective evaluation of the clinical pulmonary infection score as an early clinical predictor of outcome. Crit Care Med 2003, 31:676-682.

18. American Thoracic Society; Infectious Diseases Society of America: Guidelines for the management of adults with hospital-acquired, ventilator-associated, and healthcare-associated pneumonia. Am J Respir Crit Care Med 2005, 171:388-416.

19. Garner JS, Jarvis WR, Emori TG, Horan TC, Hughes JM: CDC definitions for nosocomial infections, 1988. Am J Infect Control 1988, 16:128-140.

20. Papazian L, Thomas P, Garbe L, Guignon I, Thirion X, Charrel J, Bollet C, Fuentes $P$, Gouin F: Bronchoscopic or blind sampling techniques for the diagnosis of ventilator-associated pneumonia. Am J Respir Crit Care Med 1995, 152:1982-1991.

21. Anand NJ, Zuick S, Klesney-Tait J, Kollef MH: Diagnostic implications of soluble triggering receptor expressed on myeloid cells-1 in BAL fluid of patients with pulmonary infiltrates in the ICU. Chest 2009, 135:641-647.

22. Huh JW, Lim CM, Koh Y, Oh YM, Shim TS, Lee SD, Kim WS, Kim DS, Kim WD, Hong SB: Diagnostic utility of the soluble triggering receptor expressed on myeloid cells- 1 in bronchoalveolar lavage fluid from patients with bilateral lung infiltrates. Crit Care 2008, 12:R6.

23. Determann RM, van Till JW, van Ruler O, van Veen SQ, Schultz MJ, Boermeester MA: sTREM-1 is a potential useful biomarker for exclusion of ongoing infection in patients with secondary peritonitis. Cytokine 2009, 46:36-34.

doi:10.1186/cc10015

Cite this article as: Ramirez et al:: Diagnostic implications of soluble triggering receptor expressed on myeloid cells- 1 in patients with acute respiratory distress syndrome and abdominal diseases: a preliminary observational study. Critical Care 2011 15:R50.

\section{Submit your next manuscript to BioMed Central and take full advantage of:}

- Convenient online submission

- Thorough peer review

- No space constraints or color figure charges

- Immediate publication on acceptance

- Inclusion in PubMed, CAS, Scopus and Google Scholar

- Research which is freely available for redistribution

Submit your manuscript at www.biomedcentral.com/submit
C) Biomed Central 